\title{
Chronic excitotoxic lesion of the dorsal raphe nucleus induces sodium appetite
}

H.R. Cavalcante-Lima' ${ }^{1}$,

D. Badauê-Passos Jr. ${ }^{2}$, W. de-Lucca Jr. ${ }^{2}$, H.R.C. Lima ${ }^{1}$, R.H. Costa-e-Sousa ${ }^{1}$, E.L. Olivares ${ }^{1}$, P.L. Cedraz-Mercez ${ }^{1}$, R.O. Reis' ${ }^{1}$, M.A. Medeiros ${ }^{1}$, W.S. Côrtes ${ }^{1}$ and L.C. Reis ${ }^{1}$

\author{
'Departamento de Ciências Fisiológicas, Instituto de Biologia, \\ Universidade Federal Rural do Rio de Janeiro, Seropédica, RJ, Brasil \\ ${ }^{2}$ Departamento de Fisiologia, Faculdade de Medicina de Ribeirão Preto, \\ Universidade de São Paulo, Ribeirão Preto, SP, Brasil
}

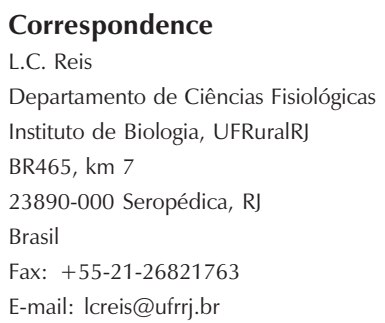

Received April 22, 2004 Accepted June 1, 2005

\begin{abstract}
We determined if the dorsal raphe nucleus (DRN) exerts tonic control of basal and stimulated sodium and water intake. Male Wistar rats weighing 300-350 g were microinjected with phosphate buffer (PBDRN, $\mathrm{N}=11$ ) or $1 \mu \mathrm{g} / 0.2 \mu \mathrm{l}$, in a single dose, ibotenic acid (IBO-DRN, $\mathrm{N}=9$ to 10 ) through a guide cannula into the DRN and were observed for 21 days in order to measure basal sodium appetite and water intake and in the following situations: furosemide-induced sodium depletion $(20 \mathrm{mg} / \mathrm{kg}, s c, 24 \mathrm{~h}$ before the experiment) and a low dose of dietary captopril ( $1 \mathrm{mg} / \mathrm{g}$ chow). From the 6th day after ibotenic acid injection IBO-DRN rats showed an increase in sodium appetite $(12.0 \pm 2.3$ to $22.3 \pm 4.6 \mathrm{ml} 0.3 \mathrm{M} \mathrm{NaCl}$ intake) whereas PB-DRN did not exceed 2 $\mathrm{ml}(\mathrm{P}<0.001)$. Water intake was comparable in both groups. In addition to a higher dipsogenic response, sodium-depleted IBO-DRN animals displayed an increase of $0.3 \mathrm{M} \mathrm{NaCl}$ intake compared to PBDRN (37.4 \pm 3.8 vs $21.6 \pm 3.9 \mathrm{ml} 300 \mathrm{~min}$ after fluid offer, $\mathrm{P}<0.001)$. Captopril added to chow caused an increase of $0.3 \mathrm{M} \mathrm{NaCl}$ intake during the first 2 days (IBO-DRN, $33.8 \pm 4.3$ and $32.5 \pm 3.4 \mathrm{ml}$ on day 1 and day 2 , respectively, $v s 20.2 \pm 2.8 \mathrm{ml}$ on day $0, \mathrm{P}<0.001$ ). These data support the view that DRN, probably via ascending serotonergic system, tonically modulates sodium appetite under basal and sodium depletion conditions and/or after an increase in peripheral or brain angiotensin II.
\end{abstract}

\section{Introduction}

The organum vasculosum laminae terminalis, median preoptic nucleus and subfornical organ (SFO), structures participating in hydroelectrolytic and cardiovascular homeostasis, receive input from serotonergic neurons of the dorsal raphe nucleus (DRN)
Key words

- Sodium appetite

- Water intake

- Dorsal raphe nucleus

- Serotonergic system

- Ibotenic acid
(1-6). There is a reciprocal connection linking DRN and SFO (7-9) which suggests that the DRN participates in cardiovascular as well as in extracellular fluid (ECF) volume and electrolyte homeostasis. Angiotensinergic stimulation of the SFO elicits electrophysiological alterations in DRN serotonergic neurons (9). On the other hand, isosmotic 
hypovolemia induced by hemorrhage evokes changes in the electrical activity of DRN serotonergic neurons connected with the SFO (10). In agreement with this, Vivas' group (11) reported c-Fos expression in DRN serotonergic neurons and laminae terminalis structures in response to salt intake under basal conditions or after sodium depletion induced by peritoneal dialysis. Furthermore, the intracerebroventricular (icv) administration of serotonin (5-HT) and of the 5-HT2A/ $\mathrm{C}$ receptor agonists induces an increase in renal sodium excretion (12). In addition, electrolytic lesions of the DRN drastically reduce the plasma levels of atrial natriuretic peptide (ANP), both in basal and ECF volume expansion situations $(6,12,13)$. In this context, it is important to note the very important role of ANP in sodium excretion and salt appetite (5,6,13-19).

Renal afferent information about tubular sodium load and plasma volume is transmitted toward forebrain areas related to angiotensin conversion (ANG I to ANG II) and subsequent angiotensin receptor activation (20). DRN afferent fibers arise from these areas (especially the SFO), probably involved in a feedback loop regulating sodium satiety and contributing to ECF volume and cardiocirculatory homeostasis $(7,9,21)$.

Taken together, this evidence supports our view that central control of sodium satiety and excretion is regulated by the serotonergic system that originates from the midbrain, but only one study acknowledged that the suppression of ascending serotonergic pathways through DRN electrolytic lesion evokes an increase in sodium appetite (21). Corroborating these findings, other investigators showed that basal c-Fos expression in serotonergic neurons of the DRN decreased after sodium depletion induced by peritoneal dialysis and increased after spontaneous and induced sodium intake, suggesting that there is a tonic inhibition of sodium appetite by serotonergic cells of this nucleus (11). Although we hypothesized the same, when working with DRN electrolytic lesion it is necessary to limit the lesion to the neuronal cell body located in the ventromedial portion of the DRN and to perform longer observations (21).

Thus, anatomic and physiological evidence clearly shows the role of the DRN in integrating viscerosensory input and forebrain signals concerning cardiovascular and hydroelectrolyte homeostasis. In this context, the objective of the present study was to investigate the influence of excitotoxic DRN lesion by local ibotenic acid microinjection on sodium appetite both in the basal condition and in the presence of natriorexigenic paradigms, such as furosemide-induced sodium depletion and low-dose dietary supplementation with captopril.

\section{Material and Methods}

\section{Animals}

Male Wistar rats weighing 300-350 g were maintained in a room with lights on from 7:00 to 19:00 h, controlled temperature at $25^{\circ} \mathrm{C}$ and free access to Purina chow and water. Before brain stereotaxic surgery the rats were housed in metabolic cages for at least 5 days. All the experimental protocols and animal procedures were carried out in accordance with current Brazilian legislation.

\section{Ibotenic lesions}

Rats were anesthetized with sodium pentobarbital (Hypnol 3\%, Fontoveter, Itapira, $\mathrm{SP}$, Brazil, $50 \mathrm{mg} / \mathrm{kg}$ body weight, ip) and a stainless steel guide cannula (0.6-mm external diameter) was stereotaxically implanted $0.2 \mathrm{~mm}$ above the DRN. The following coordinates were used: anteroposterior, 7.6-7.8 $\mathrm{mm}$ posterior to bregma; lateral, $0.0 \mathrm{~mm}$ from midline; vertical, $6.4-6.6 \mathrm{~mm}$ from skull calvaria (22). Ibotenic acid microinjections $(1 \mu \mathrm{g} / 0.2 \mu \mathrm{l}$ dissolved in sterile $0.2 \mathrm{M}$ so- 
dium phosphate buffer, $\mathrm{pH}$ 7.4) were performed during a period of $1 \mathrm{~min}$. Shamlesioned rats were microinjected with $0.2 \mu \mathrm{l}$ phosphate buffer. A prophylactic dose of penicillin was administered to operated rats (30,000 IU, im; Fort Dodge Saúde Animal Ltda., Campinas, SP, Brazil). Data from rats with lesions outside the dorsoventromedial region of the DRN were not included in the statistical analysis.

\section{Experimental procedures}

DRN-excitotoxic-lesioned rats microinjected with ibotenic acid (IBO-DRN) or sham-lesioned rats microinjected with sodium phosphate buffer (PB-DRN) were used in three experimental protocols:

Group 1. IBO-DRN $(\mathrm{N}=10)$ and PBDRN $(\mathrm{N}=11)$ rats were maintained in metabolic cages under basal conditions to measure water and $0.3 \mathrm{M} \mathrm{NaCl}$ consumption for 21 days following surgery.

Group 2. On day 21 after microinjection, IBO-DRN (N = 9) and PB-DRN ( $=11)$ rats were submitted to sodium and water depletion induced by $20 \mathrm{mg} / \mathrm{kg}$ furosemide, sc (Lasix, Aventis Pharma, Suzano, SP, Brazil). During the $24 \mathrm{~h}$ following furosemide administration a low-sodium diet was offered to the animals (23). Distilled water and $0.3 \mathrm{M} \mathrm{NaCl}$ were then supplied and the consumption of these fluids was recorded hourly for $5 \mathrm{~h}$ and at the end of $24 \mathrm{~h}$ (Figure 1).

Group 3. A low dose (1 mg/g of chow) of dietary captopril (Bristol-Myers Squibb, São Paulo, SP, Brazil) was added every day to the chow from the 6th to the 11th days after surgery (PB-DRN, N = 11 and IBODRN, $N=10$ ). This model promotes a systemic rise in plasma ANG I levels, which results in an elevated ANG II synthesis in circumventricular forebrain structures underlying the subsequent natriorexigenic response (24-29). The consumption of $0.3 \mathrm{M}$ $\mathrm{NaCl}$ and water was determined before (3day pretreatment period), during (captopril treatment) and after treatment (9-day recovery period).

\section{Histological analysis}

Rats were anesthetized and transcardially perfused with $4 \%$ paraformaldehyde to identify the lesion site. Brains were removed and serial coronal sections were examined after staining with crystal violet by the Holzer method.

\section{Statistical analysis}

Differences between the IBO-DRN and PB-DRN groups were analyzed by repeated measures two-way ANOVA followed by the Newman-Keuls test, with the level of significance set at $5 \%$.

\section{Results}

The experimental protocol is presented schematically in Figure 1. Midbrain histological analyses of IBO-DRN rats revealed typical lesions in the ventromedial portion of the DRN. Fibrillar astrocytes were evident along the anteroposterior axis of this nucleus (Figure 2).

Sodium appetite was increased in IBODRN rats compared to PB-DRN rats throughout the experimental period, especially after 6 days post-lesion $(\mathrm{P}<0.01)$. From day 11 on, $0.3 \mathrm{M} \mathrm{NaCl}$ intake reached a level always higher than $18 \mathrm{ml}$ (Figure 3A), what persisted up to the 35th day post-lesion (data

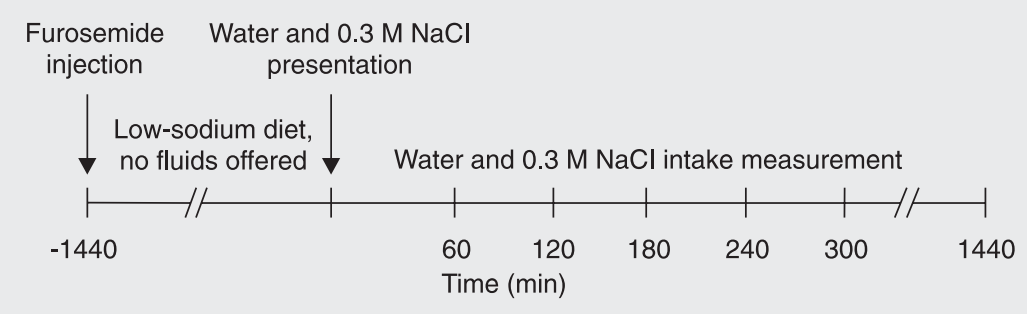

Figure 1. Schematic representation of the experimental protocol used to evaluate $0.3 \mathrm{M}$ $\mathrm{NaCl}$ and water intake in rats submitted to furosemide-induced sodium depletion. 
Figure 2. Reactive gliosis in rats with an excitotoxic lesion of the dorsal raphe nucleus induced by microinjection of ibotenic acid. Coronal section at the midbrain level shows fibrillar astrocytes in its ventromedial portion (arrowheads). $\mathrm{Aq}=$ aqueduct. Holzer technique. Magnification, 100X.

Figure 3. Effect of excitotoxic lesion of the dorsal raphe nucleus produced by ibotenic acid microinjection (IBO-DRN, $\mathrm{N}=10$ ) on chronic ingestion of $0.3 \mathrm{M} \mathrm{NaCl}$ (A) and water (B) by IBO-DRN rats and by sham-lesioned rats microinjected with sodium phosphate buffer (PB-DRN, N = 11) Data are reported as mean \pm SEM. *P $<0.05$ compared to PBDRN rats (two-way ANOVA followed by Newman-Keuls test). not shown). In addition, most of the IBODRN rats showed a drive to eat salt, which was evident when a salt lump was offered through the metabolic cage door. This phenomenon was frequently observed in rats which had been previously offered the salt lump. Water intake did not differ between groups during the experimental period (Figure $3 \mathrm{~B})$.

Furosemide-induced sodium and water depletion enhanced the natriorexigenic response of IBO-DRN, which became significantly higher than that of PB-DRN only after 240 min of fluid offer, remaining at this level
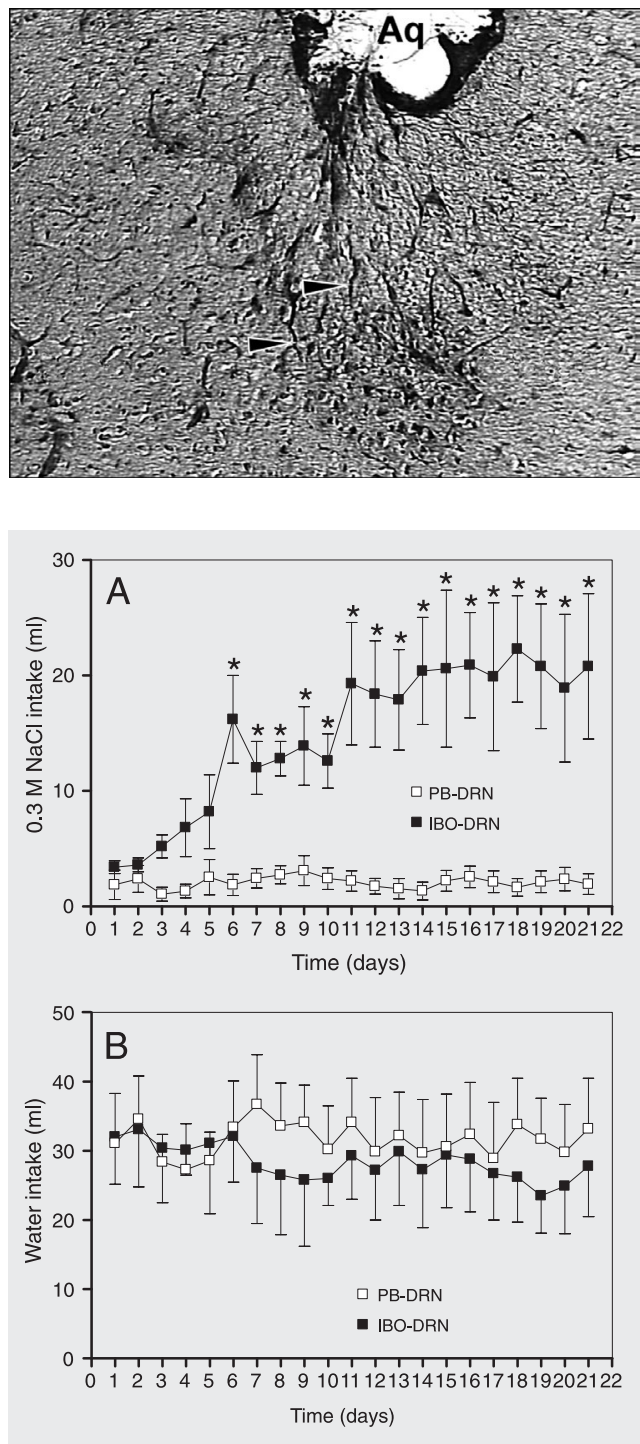

for $24 \mathrm{~h}(9.8 \pm 1.0,10.2 \pm 1.0$, and $21.6 \pm 3.9$ vs $13.1 \pm 0.98,15.3 \pm 1.1$, and $37.4 \pm 3.8 \mathrm{ml}$, at 240, 300, and $1440 \mathrm{~min}$ in PB-DRN and IBO-DRN, respectively, $\mathrm{P}<0.04$; Figure 4A). Renal sodium and water loss-induced volume depletion evoked an increased water intake in IBO-DRN animals during the experimental period up to $24 \mathrm{~h}$ after fluid presentation $(\mathrm{P}<0.002$; Figure 4B).

Low-dose captopril treatment promoted a still higher increase in $0.3 \mathrm{M} \mathrm{NaCl}$ intake in IBO-DRN animals and was significantly different compared to the PB-DRN group on the first 2 days of treatment $(13.6 \pm 1.7$ and $20.8 \pm 2.2 v s 33.8 \pm 4.3$ and $32.5 \pm 3.4 \mathrm{ml}$ on the 1st and 2nd days in PB-DRN and IBODRN, respectively, $\mathrm{P}<0.002$; Figure 5A). On the first day after the end of captopril treatment there was an abrupt fall of $0.3 \mathrm{M}$ $\mathrm{NaCl}$ intake in the IBO-DRN group from $30.1 \pm 3.3$ to $7.9 \pm 3.3 \mathrm{ml}$. In contrast, PBDRN rats showed a slight reduction compared to IBO-DRN rats (from $27.5 \pm 3.0$ to $19.4 \pm 4.1 \mathrm{ml}$ ), with higher levels of $0.3 \mathrm{M}$ $\mathrm{NaCl}$ intake than IBO-DRN at this time point. The $0.3 \mathrm{M} \mathrm{NaCl}$ intake was gradually recovered after day 12 (6 days after the end of captopril treatment) in both groups, returning to levels similar to those observed before captopril treatment. There was no difference in water intake between the groups during 14 days, except on the first two days after captopril treatment interruption when an increase in this parameter was observed in IBO-DRN rats (Figure 5B).

\section{Discussion}

Our results show that DRN lesions disrupt the functional integrity of central neural pathways that normally exert a negative drive leading to salt intake inhibition. It has been postulated that the DRN serotonergic neurons receive viscerosensory inputs concerning renal sodium load and/or ECF volume variations to trigger homeostatic regulation of sodium appetite $(6,21,30)$. This view has 
been shared by other investigators who have shown increased c-Fos expression in DRN serotonergic neurons after salt intake under both basal and sodium depletion conditions (11).

Low-dose captopril treatment resulted in a higher saline intake by ibotenic DRNlesioned rats, suggesting that there is either an enhanced capacity of ANG I conversion to ANG II in forebrain structures, or an increased sensitivity to ANG II-evoked sodium appetite $(24,25,27-29)$. On this basis and regarding reciprocal relationships between SFO and DRN, we postulated that the presumptive angiotensinergic sensitivity of the SFO is enhanced following the failure of inhibitory signals arising from the midbrain $(7,10,28)$.

Although we did not investigate the forebrain angiotensinergic sensitivity, we recently demonstrated that experiments involving an increase in plasma ANG II levels exarcebate the sodium appetite of iboteniclesioned rats (31). Hence, the view that suppression of neural pathways originating in the DRN reduces the threshold of the sodium appetite response through an increase in angiotensinergic sensitivity of SFO neurons should be considered. That is, lesioned rats putatively respond to the natriorexigenic stimuli (induced by high plasma levels of ANG I or ANG II) which would be subthreshold for sham-lesioned rats.

Also, we did not rule out the possibility that the deficit in the ascending regulation of sodium appetite is due, at least in part, to disruption of interconnections between the DRN and lateral parabrachial nucleus (LPBN) $(32,33)$. This presumptive interaction was suggested by Lind's work (7), which presupposed that viscerosensory information relayed from the pontine nucleus towards the raphe would be transmitted to the SFO through ascending serotonergic pathway from the DRN. The LPBN is an important pontine circuit that receives homeostatic viscerosensory signals from the right atrium and vena cava stretch receptors and arterial and atrial baroreceptors implicated in the control of extracellular volume and blood pressure (34).
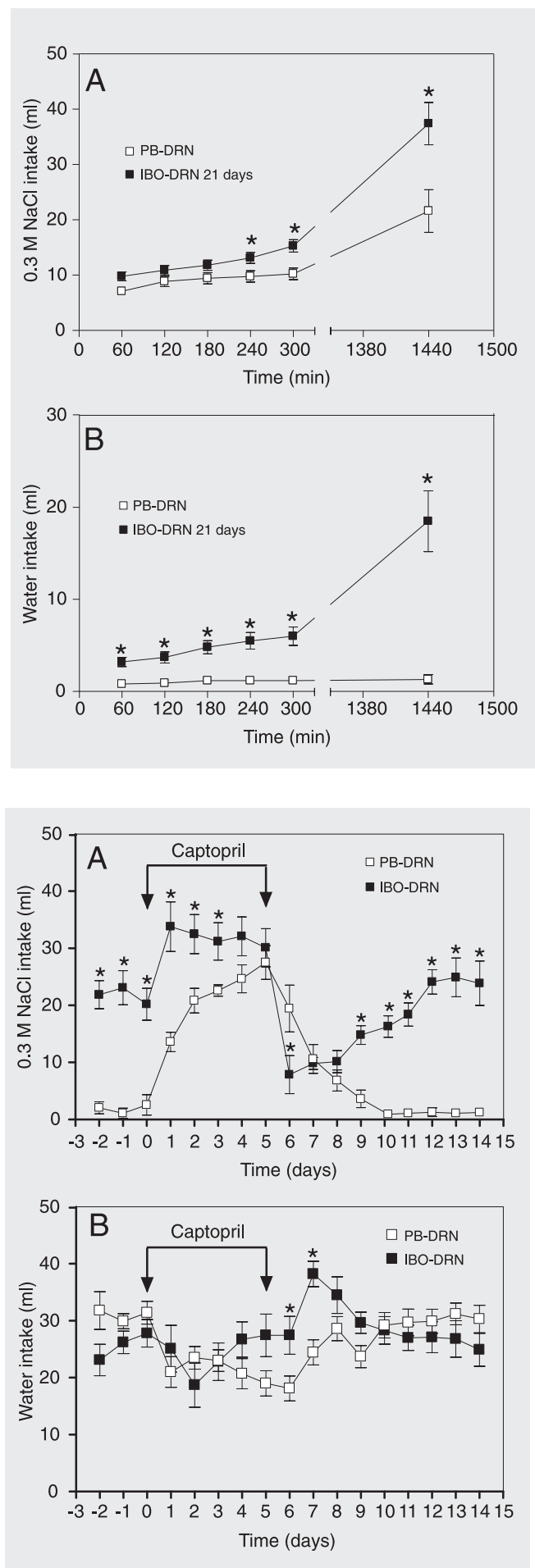

Figure 4. Effect of furosemide treatment $(20 \mathrm{mg} / \mathrm{kg}, s c, 24 \mathrm{~h}$ before the beginning of the experiment) on the cumulative ingestion of $0.3 \mathrm{M} \mathrm{NaCl}(\mathrm{A})$ and water $(\mathrm{B})$ by rats with excitotoxic lesion of the dorsal raphe nucleus produced by ibotenic acid microinjection (IBO-DRN, $\mathrm{N}=9$ ) and sham-lesioned rats microinjected with phosphate buffer (PB-DRN, $N=11$ ). Data are reported as mean \pm SEM. ${ }^{*} \mathrm{P}<$ 0.05 compared to $\mathrm{PB}-\mathrm{DRN}$ rats (two-way ANOVA followed by Newman-Keuls test).

Figure 5. Effect of dietary captopril treatment (1 $\mathrm{mg} / \mathrm{g}$ of food) on chronic ingestion of $0.3 \mathrm{M}$ $\mathrm{NaCl}(\mathrm{A})$ and water (B) by rats with excitotoxic lesion of the dorsal raphe nucleus produced by ibotenic acid microinjection (IBO-DRN, $\mathrm{N}=10$ ) and by sham-lesioned rats microinjected with phosphate buffer microinjection (PB-DRN, $\mathrm{N}=11$ ). Data are reported as means \pm SEM. * $\mathrm{P}<0.05$ compared to $\mathrm{PB}$ DRN rats (two-way ANOVA followed by Newman-Keuls test). 
The blockade of 5 -HT2A/C receptors in the LPBN exacerbates the ingestion of hypertonic saline induced by $i c v$ administration of ANG II or by a combination of furosemide + low dose of captopril (23). Microinjection of the AT1 antagonist losartan into the SFO prevented the additional salt intake induced by methysergide administration in the LPBN of rats submitted to furosemide + captopril treatment (35). Later, Menani and colleagues $(36,37)$ showed a widespread involvement of the inhibitory serotonergic mechanism in the LPBN. Thus, bilateral injections of serotonergic receptor antagonist methysergide amplified hypertonic saline intake after furosemide-induced sodium depletion, water deprivation or central cholinergic stimulation.

Corroborating data obtained by electrolytic DRN lesion (21), our results reveal that excitotoxic damage of DRN neurons induces a rise in basal $\mathrm{NaCl}$ intake. In that study (21), Olivares and co-workers made short-term observations ( 3 days only) and their findings correlated with reduced ANP level in electrolytic DRN-lesioned rats under basal and volume expansion conditions (13). Although the reduced ANP levels could explain the increase in sodium appetite, it has been demonstrated that renal sodium excretion normalizes 7 days after electrolytic lesion of the DRN, possibly concomitant with a restoration of ANP secretion $(6,13)$.

Therefore, on the basis of the present data, the above-mentioned observation con- flicts with the hypothesis that DRN lesionevoked sodium appetite occurs as a result of reduced ANP secretion. We suggested that the suppression of ascending serotonergic pathways exacerbates sodium appetite through a disinhibitory mechanism in the forebrain, possibly within the SFO, whose target neurons would be ANG II-sensitive. However, the precise mechanism that underlies forebrain mediation of serotonergic sodium satiety is unknown.

Our data suggest that an ascending circuit, possibly serotonergic, originating in the DRN, integrates viscerosensory and forebrain signals for sodium appetite homeostasis. The results obtained under basal conditions allow us to postulate that the DRN neural circuit constitutes an integrative system that tonically triggers modulation of the outputs to the forebrain to induce salt satiety. Furthermore, disruption of the reciprocal connection between DRN and LPBN could contribute to the deficit in forebrain signaling for sodium appetite modulation.

\section{Acknowledgments}

The authors are grateful to Mr. Ipojucan Pereira de Souza for animal care. We are indebted to Dr. Celso Rodrigues Franci of the Department of Physiology (Faculty of Medicine of Ribeirão Preto, University of São Paulo) for his support in the Holzer technique.

\section{References}

1. Azmitia EC \& Segal M (1978). An autoradiographic analysis of the differential ascending projections of the dorsal and median raphe nuclei in the rat. Journal of Comparative Neurology, 179: 641-668.

2. Steinbusch HWM (1981). Distribution of serotonin-immunoreactivity in the central nervous system of the rat cell bodies and terminals. Neuroscience, 6: 557-618.

3. Bosler O \& Descarries L (1988). Monoamine innervation of the organum vasculosum laminae terminalis (OVLT): a high resolution radioautographic study in the rat. Journal of Comparative Neurology, 272: 545-561.

4. Marcinkiewicz M, Morcos R \& Chretien M (1989). CNS connections with the raphe nucleus: retrograde tracing with WGA-apoHRP-Gold complex in the rat. Journal of Comparative Neurology, 289: 11-35.

5. McCann SM, Gutkowska J \& Antunes-Rodrigues J (2003). Neuroendocrine control of body fluid homeostasis. Brazilian Journal of Medical and Biological Research, 36: 165-181.

6. Antunes-Rodrigues J, Castro M, Elias LLK et al. (2004). Neuroendocrine control of body fluid metabolism. Physiological Reviews, 84: 169-208.

7. Lind RW (1986). Bi-directional, chemically specified neural connections between the subfornical organ and the midbrain raphe system. Brain Research, 384: 250-261. 
8. Scrogin KE, Johnson AK \& Herbert AS (1998). Multiple receptor subtypes mediate the effects of serotonin on rat subfornical organ neurons. American Journal of Physiology, 275: R2035-R2042.

9. Tanaka J, Ushigome A, Hori K et al. (1998). Responses of raphe nucleus projecting subfornical organ neurons to angiotensin II in rats. Brain Research Bulletin, 45: 315-318.

10. Tanaka J, Okumura T, Sakamaki K et al. (2001). Activation of serotonergic pathways from the midbrain raphe system to the subfornical organ by hemorrhage in the rat. Experimental Neurology, 169: 156-162.

11. Franchini $L H$, Johnson AK \& Vivas $L$ (2002). Sodium appetite and Fos activation in serotonergic neurons. American Journal of Physiology, 282: R235-R243.

12. Reis LC, Ramalho MJ \& Antunes-Rodrigues J (1991). Effect of central administration of serotoninergic agonists on electrolyte excretion control. Brazilian Journal of Medical and Biological Research, 24: 633-641.

13. Reis LC, Ramalho MJ, Favaretto ALV et al. (1994). Participation of the ascending serotonergic system in the stimulation of atrial natriuretic peptide release. Proceedings of the National Academy of Sciences, USA, 91: 12022-12026.

14. DeBold AJ, Borenstein HB, Veress AT et al. (1981). Rapid and potent natriuretic response to intravenous injection of atrial myocardial extract in rats. Life Sciences, 28: 89-94.

15. DeBold AJ, DeBold K, Boer PH et al. (1991). A decade of atrial natriuretic factor research. Canadian Journal of Physiology and Pharmacology, 69: 1480-1485.

16. Antunes-Rodrigues J, McCann SM \& Samson WK (1985). Atrial natriuretic factor inhibits dehydration- and angiotensin II-induced water intake in the conscious, unrestrained rat. Proceedings of the National Academy of Sciences, USA, 82: 8720-8723.

17. Antunes-Rodrigues J, McCann SM, Rogers LC et al. (1986). Central administration of atrial natriuretic factor inhibits saline preference in the rat. Endocrinology, 118: 1726-1728.

18. Antunes-Rodrigues J, Ramalho MJ, Reis LC et al. (1991). Lesions of the hypothalamus and pituitary inhibit volume-expansion-induced release of atrial natriuretic peptide. Proceedings of the National Academy of Sciences, USA, 88: 2956-2960.

19. Antunes-Rodrigues J, Machado $\mathrm{BH}$, Andrade $\mathrm{HA}$ et al. (1992). Carotid-aortic and renal baroreceptors mediate the atrial natriuretic peptide release induced by blood volume expansion. Proceedings of the National Academy of Sciences, USA, 89: 6828-6831.

20. Fitch GK \& Weiss ML (2000). Activation of renal afferent pathways following furosemide treatment. II. Effect of angiotensin blockade. Brain Research, 861: 377-389.

21. Olivares EL, Costa-e-Sousa HR, Cavalcante-Lima HR et al. (2003). Effects of electrolytic lesion of dorsal raphe nucleus on water intake and sodium appetite. Brazilian Journal of Medical and Biological Research, 36: 1709-1716.

22. Paxinos G \& Watson C (1986). The Rat Brain in Stereotaxic Coordi- nates. 2nd edn. Academic Press, New York.

23. Menani JV, Thunhorst RL \& Johnson AK (1996). Lateral parabrachial nucleus and serotonergic mechanisms in the control of salt appetite in rats. American Journal of Physiology, 270: R162-R168.

24. Fregly MJ (1980). Effects of the angiotensin converting enzyme inhibitor, captopril on $\mathrm{NaCl}$ appetite of rats. Journal of Pharmacology and Experimental Therapeutics, 215: 407-412.

25. Elfon RM, Epstein NA \& Fitzsimons JT (1984). Involvement of the renin-angiotensin system in captopril-induced sodium appetite in the rat. Journal of Physiology, 354: 11-27.

26. Thunhorst RL, Fitts DA \& Simpson JB (1989). Angiotensin-converting enzyme in subfornical organ mediates captopril-induced drinking. Behavioral Neuroscience, 103: 1302-1310.

27. Thunhorst RL, Beltz TG \& Johnson AK (1999). Effects of subfornical organ on acutely induced thirst and salt appetite. American Journal of Physiology, 277: R56-R65.

28. Fitzsimons JT (1998). Angiotensin, thirst, and sodium appetite. Physiological Reviews, 78: 583-686.

29. Ventura RR, Olivares EL, Badauê-Passos Jr D et al. (2001). Effect of chronic oral administration of a low dose of captopril on sodium appetite of hypothyroid rats. Influence of aldosterone treatment. Brazilian Journal of Medical and Biological Research, 34: 407-411.

30. Badauê-Passos Jr D, Ventura RR, Silva LFS et al. (2003). Effect of brain serotoninergic stimulation on sodium appetite of euthyroid and hypothyroid rats. Experimental Physiology, 88: 252-260.

31. Cavalcante-Lima HR, Lima HRC, Costa-e-Sousa RH et al. (2005). Dipsogenic stimulation in ibotenic DRN-lesioned rats induces concomitant sodium appetite. Neurocience Letters, 374: 5-10.

32. Petrov T, Krukoff TL \& Jhmandas JH (1992). The hypothalamic paraventricular and lateral parabrachial nuclei receive collaterals from raphe nucleus neurons: a combined double retrograde and immunocytochemical study. Journal of Comparative Neurology, 318: 18-26.

33. Petrov T, Jhmandas JH \& Krukoff TL (1992). Characterization of peptidergic efferents from the lateral parabrachial nucleus to identified neurons in the dorsal raphe nucleus. Journal of Chemical Neuroanatomy, 5: 367-373.

34. Johnson AK \& Thunhorst RL (1997). The neuroendocrinology of thirst and salt appetite: Visceral sensory signals and mechanisms of central integration. Frontiers in Neuroendocrinology, 18: 292-353.

35. Menani JV, Colombari DS, Beltz TG et al. (1998). Salt appetite: interaction of forebrain angiotensinergic and hindbrain serotonergic mechanisms. Brain Research, 801: 29-35.

36. Menani JV, De Luca Jr LA \& Johnson AK (1998). Lateral parabrachial nucleus mechanisms and salt appetite induced by sodium depletion. American Journal of Physiology, 274: R555-R560.

37. Menani JV, De Luca Jr LA, De Gobbi Jl et al. (2002). Serotonergic mechanisms of the lateral parabrachial nucleus and cholinergicinduced sodium appetite. American Journal of Physiology, 282: R837-R841. 